\title{
Saliva as a Biological Sample for COVID-19 Diagnosis?
}

\author{
Kafle $D,{ }^{1}$ Sapkota $D^{2}$
}

\author{
${ }^{1}$ Department of Orthodontics, \\ Kathmandu University School of Medical Sciences, \\ Dhulikhel, Nepal. \\ ${ }^{2}$ Department of Oral Biology, \\ Faculty of Dentistry, University of Oslo, \\ Sognsvannsveien 10, Domus Odontologica, \\ 0372 Oslo, Norway.

\section{Corresponding Author} \\ Dipak Sapkota \\ Department of Oral Biology, \\ Faculty of Dentistry, University of Oslo, \\ Sognsvannsveien 10, Domus Odontologica, \\ 0372 Oslo, Norway \\ E-mail: dipak.sapkota@odont.uio.no
}

Citation

Kafle D, Sapkota D. Saliva as a Biological Sample for COVID-19 Diagnosis? Kathmandu Univ Med J. 2020; COVID-19 Special Issue 70(2):107-10.

\begin{abstract}
The COVID-19 pandemic, caused by severe acute respiratory syndrome corona virus 2 (SARS-CoV-2), has become a severe global health problem affecting almost every country in the world. Compared to other coronaviruses, SARS-CoV- 2 is considered to be more infectious thereby leading to a rapid spread of this disease across the world. The effective control of this disease relies on timely diagnosis, proper isolation, contact tracing of the infected people and segregation of vulnerable group from potential contamination. Currently, the gold standard diagnostic test for COVID-19 is real-time reverse transcriptase polymerase chain reaction (RT-PCR) using nasopharyngeal swab (NPS). However, NPS collection has several shortcomings. Besides requiring an active involvement of healthcare personnel and personal protective equipment (PPE), NPS collection is uncomfortable for the patient as it can induce coughing, gagging, vomiting and even bleeding. Evidence from current studies indicates that saliva has a potential to be useful as an alternative biological sample for COVID-19 diagnosis. Indeed, saliva as a biological sample offers several advantages over NPS. Saliva collection is better accepted by patients, it can be self-collected and does not require PPE and active involvement of healthcare personnel. Moreover, preliminary results indicate that the sensitivity and specificity of saliva for COVID-19 diagnosis is similar to that of NPS. This summarizes recent observations in the field and discusses the potential use of saliva for COVID-19 diagnosis.
\end{abstract}

\section{KEY WORDS}

Diagnosis, Saliva, SARS-CoV-2, Real time PCR

\section{INTRODUCTION}

Pandemic incidents are rare in the history of mankind. Before COVID-19, the deadliest pandemic, last seen immediately after the World War I in 1918, was a flu pandemic which claimed 50-100 million lives worldwide. ${ }^{1}$ The pandemic lasted for 2 years, affected one-quarter of the world's population and took more lives than did world war I. Almost 100 years later, there is another outbreak, the pandemic known as COVID-19 (Corona Virus Disease -2019), which is caused by severe acute respiratory syndrome corona virus 2 (SARS-CoV-2). SARS-CoV-2 is believed to have been transmitted to human from bat, and is genetically similar to both 2003 SARS-CoV and 2013 MERS-CoV. ${ }^{2,3}$ It is difficult to imagine that an outbreak of a viral infection in the twenty-first century, when science and technological advances have led to artificial intelligence gradually taking over human tasks, would cause the whole world to stand still for several months.
The pneumonia caused by SARS-CoV-2 was first reported in December 2019 in the city of Wuhan, China. ${ }^{4}$ In the third week of July 2020, the death toll has already exceeded 648,000 and the number of infected totals over 16.2 million. ${ }^{5}$ There are no signs that the spread of COVID-19 and accompanying death toll will end soon. WHO has already predicted that the COVID-19 pandemic will last for 18-24 months. ${ }^{6}$ According to a recent press release from United Nations Development Program (UNDP), this outbreak has pushed millions of people into poverty, hunger and malnutrition. ${ }^{7}$ The global economy has been hit hard by this crisis and socioeconomic impact is extensive.

Because of the highly contagious nature of the SARSCoV-2 virus, controlling of disease has become challenging. Though the virus shares a high degree of genetic similarity with SARS-CoV and MERS-CoV, there is some speculation that it may have mutated into a more contagious form than its predecessors, which is clinically supported by the 
recent global outbreak in a short period of time. ${ }^{8,9}$ Though the mode of transmission of SARS- CoV- 2 is from human to human, there are still controversies and conflicting opinions on the pathophysiology of disease process. ${ }^{10-12}$

The effective control of this disease lies in timely diagnosis, proper isolation, contact tracing of the infected people and segregation of vulnerable groups from potential contamination. ${ }^{13,14}$ Although a number of molecular techniques (such as real-time reverse transcriptase polymerase chain reaction ( RT-PCR), enzyme immunoassay) and biological samples (such as blood, saliva, gingival fluid, stool, urine) have been used for COVID-19 diagnosis, RTPCR using nasopharyngeal swab (NPS) as a biological sample is considered to be the gold standard for laboratory diagnosis of COVID-19. Nevertheless, the collection of NPS is associated with a number of limitations related to patient comfort, safety of healthcare personnel (HCP) and usage of personal protective equipment (PPE). NPS collection is less acceptable to patients as it can induce coughing, vomiting or gag reflex and sometimes even cause bleeding at the site of swab collection. ${ }^{15}$ This is especially important during disease monitoring where repeat testing is necessary. As NPS collection requires an active involvement of $\mathrm{HCP}$, it involves a high risk of disease transmission to the HCP and patients in the hospital despite the use of PPE. It has been reported that significant numbers of doctors and paramedical staff were infected with SARS-CoV-2 even after taking precautionary measures, leading to a death rate of $1.1 \%$ among HCP. ${ }^{16}$ In addition, NPS-based diagnosis overburdens the healthcare system as it requires a procedure room, involvement of skilled HCP and other armamentarium such as PPE, viral transport medium (VTM) and swab sticks. Hence, there is an immediate need to identify a reliable alternative biological specimen for COVID-19 diagnosis and monitoring.

Saliva is emerging as a potential alternative to NPS for COVID-19 diagnosis. ${ }^{17}$ There is no denial that SARS-CoV-2 is transmitted via droplets and aerosols generated from respiratory tract secretions and saliva. ${ }^{18,19}$ If the saliva content has sufficient viral load to cause human to human transmission, then it might be possible to use saliva for the diagnosis of disease as well. Saliva is secreted by three pairs of major (parotid, submandibular and sublingual) salivary glands and numerous minor salivary glands located in oral and lip mucosa. Saliva is composed of water (99\%) and a mixture of proteins, enzymes, cytokines, immunoglobulins, mucins, electrolytes, nitrogenous compounds and other organic and inorganic compounds. ${ }^{20}$ Several constituents of saliva have been shown to be differentially expressed in disease states and accordingly, there is a high interest in saliva based diagnostics and biomarker studies. ${ }^{21,22}$

\section{Advantage of Saliva over NPS}

Saliva as a biological sample for COVID-19 diagnosis bypasses to a large extent the limitations associated with
NPS. Most importantly, saliva can be self-collected by the patients, thereby reducing the risk of disease transmission to health care workers. Saliva itself can preserve virus for a short period of time whereas the viral particles in NPS need to be preserved in VTM. ${ }^{23}$ Saliva collection does not need expensive set up and armamentarium, unlike NPS collection.

\section{Source of SARS-CoV-2 virus in saliva}

Apart from clinical advantages, there seems to be a sound scientific background for the use of saliva as a biological sample for COVID-19 diagnosis. Saliva is a good reservoir for viruses that originate from oral shedding, and secretions from the lower respiratory tract, nasopharynx and possibly infected salivary glands. ${ }^{24-26}$ In parallel, saliva is found to contain live SARS-CoV-2 and the viral load seems to be highest one week after of the onset of symptoms. ${ }^{27}$ Two main pathways for the presence of SARS-CoV-2 in saliva have been suggested. First, SARS-CoV-2 can be transported to saliva from nasopharyngeal and lower respiratory tract secretions and droplets (fig. 1). ${ }^{17}$ Secondly, SARS-CoV-2 can be secreted to saliva from the infected salivary glands (fig. 1). In line with this suggestion, epithelial cells in the salivary glands have been shown to be the initial targets for SARS-CoV in Rhesus monkeys. ${ }^{28}$ In addition, angiotensinconverting enzyme 2 (ACE2), a main surface receptor type for SARS-CoV-2, has been shown to be expressed in human salivary glands. ${ }^{29}$ Besides the salivary glands, other locations in the oral cavity such as the tongue and floor of the mouth have been shown to express high levels of ACE2. ${ }^{30}$ This observation indicates that the oral mucosa can

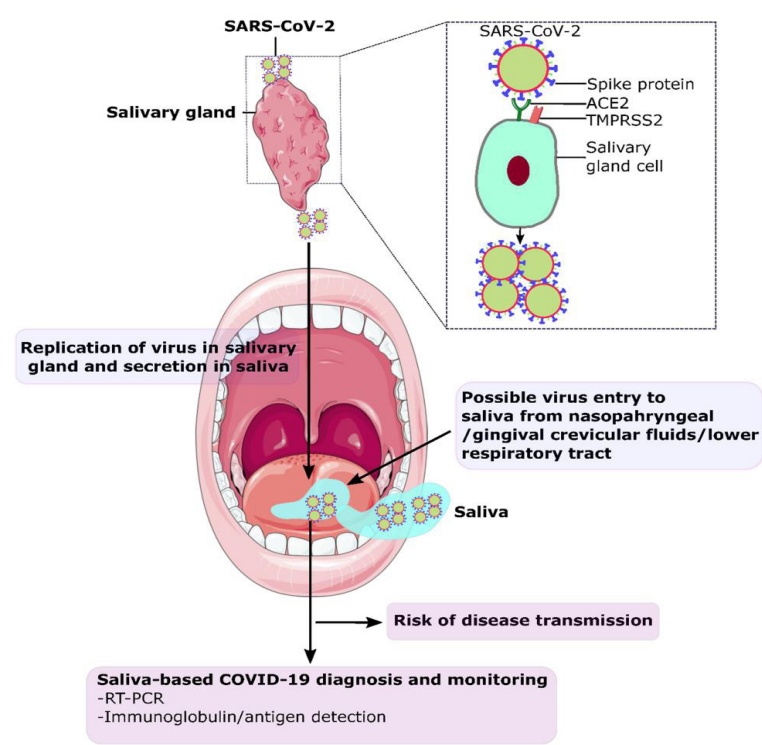

Figure 1. Illustration showing possible mechanism of viral entry to Salivary gland and sources of SARS-CoV-2 in saliva. The viral spike protein has been suggested to bind with the ACE2 receptor on the surface of salivary gland cells, followed by priming of spike protein with serine protease TMPRSS2 and subsequent entry into the cells. After replication and subsequent packaging, the new virus particles are released from the salivary gland cells into the saliva. 
be a target for SARS-CoV-2 entry and further supports the use of saliva for COVD-19 diagnostics.

\section{Current evidence for and against the use of saliva for the diagnosis of Covid-19}

Recent studies have shown promising results supporting the use of saliva for COVID-19 diagnosis. ${ }^{27,31-35}$ To et al. from Hong Kong showed that the sensitivity of salivabased SARS-CoV-2 detection was 91\%.34,36 The authors further reported a high viral load in oropharyngeal saliva during the early stage of COVID-19, and suggested that this could be one of the reasons for the highly contagious nature of the disease. Studies by Kojima et al. and Aziz et al. suggested that the sensitivity of saliva-based COVID-19 diagnosis was similar to or even better than that of NPS. ${ }^{27,33}$ Kojima and colleagues compared the concordance of self-collected saliva and nasal swab (mid turbinate) with clinician collected nasopharyngeal swab. They found that the sensitivity of self-collected saliva was higher (90\%) as compared with the clinician collected nasopharyngeal swab (85\%) and self-collected nasal swab for the diagnosis of COVID-19. Azzi et al also found that saliva could be a reliable alternative to NPS with $100 \%$ concordance with NPS testing. ${ }^{27}$ Similar results were reported by Wyllie et al. ${ }^{32}$ In addition, the authors found saliva to be positive for COVID-19 even after the NPS tested negative. This indicates that virus may be present in saliva for a longer duration than in nasopharyngeal swab. According to Han et al. significant viral load was detected for more than 3 weeks in faecal and saliva samples of symptomatic and asymptomatic COVID-19 positive patients. ${ }^{37}$ Despite the promising results presented above, a study from Becker et al found the sensitivity of saliva to be $30 \%$ less than that of NPS for COVID-19 diagnosis. ${ }^{38}$ This underscores that more studies using saliva samples from a large number of

\section{REFERENCES}

1. Salzberger B, Mohr A, Hitzenbichler F. [The Pandemic Influenza 1918]. Deutsche medizinische Wochenschrift (1946). 2018;143(25):1858-63.

2. Petrosillo N, Viceconte G, Ergonul O, Ippolito G, Petersen E. COVID-19, SARS and MERS: are they closely related? Clinical Microbiology and Infection. 2020;26(6):729-34.

3. Gilbert GL. SARS, MERS and COVID-19 -new threats; old lessons. International Journal of Epidemiology. 2020.

4. World Health Organization 2019-nCoV Situation report - 121 January 2020. https://www.who.int/docs/ default-source/ coronaviruse/ situation-reports/20200121- sitrep-1-2019.ncov.pdf.

5. World Health Organization Novel Coronavirus (COVID-2019) situation reports. https://experience.arcgis.com/experience/685d0ace521648 f8a5beeee1b9125cd

6. www.who.int/covid-19/information

7. www.undp.org

8. Wang H, Li X, Li T, Zhang S, Wang L, Wu X, et al. The genetic sequence, origin, and diagnosis of SARS-CoV-2. European journal of clinical microbiology and infectious diseases: official publication of the European Society of Clinical Microbiology. 2020:1-7.
COVID-19 patients with different severity are needed to determine the sensitivity and specificity of saliva-based COVID-19 diagnosis and disease monitoring.

\section{Saliva-based immunoassays}

Using serum and plasma samples, recent studies have shown promising results for the detection of immunoglobulins (IgG and IgM) against SARS-CoV-2 in COVID-19 patients. ${ }^{39,40}$ Unlike RT-PCR, the immunological testing can identify both current and previous infection status. In the past, salivary immunoglobulins were used for the diagnosis of different viral diseases. ${ }^{41,42}$ However, the presence of SARS-CoV-2 specific antibodies has not been investigated in saliva so far. SARS-CoV-specific secretory IgA were detected in the saliva of mice intranasally immunized with SARS-CoV virus like particles. ${ }^{43}$ Hence, it is possible that anti- SARS-CoV-2 antibodies might be present in human saliva. However, this suggestion warrants further studies. If saliva can be used instead of blood, widespread immunological testing can be administered at a community level, benefitting rural and resource deprived areas.

\section{CONCLUSION}

The use of saliva for the diagnosis of COVID-19 seems promising. There are not only a number of clinical advantages of saliva over other sample types, but the use of saliva also seems to have a reasonable scientific basis. So, the use saliva as an alternative to NPS should be considered. However, more studies using saliva samples from a large number of COVID-19 patients are needed to determine the sensitivity and specificity of saliva-based COVID-19 diagnosis and disease monitoring before salivabased COVID-19 test is available for clinical use.

9. Rabaan AA, Al-Ahmed SH, Haque $S$, Sah R, Tiwari R, Malik YS, et al SARS-CoV-2, SARS-CoV, and MERS-COV: A comparative overview. Le infezioni in medicina. 2020;28(2):174-84.

10. Fani M, Teimoori A, Ghafari S. Comparison of the COVID-2019 (SARSCoV-2) pathogenesis with SARS-CoV and MERS-CoV infections. Future Virology.0(0):null.

11. Yuki K, Fujiogi M, Koutsogiannaki S. COVID-19 pathophysiology: A review. Clinical immunology (Orlando, Fla). 2020;215:108427.

12. Mason RJ. Pathogenesis of COVID-19 from a cell biology perspective. European Respiratory Journal. 2020;55(4):2000607.

13. Adhikari SP, Meng S, Wu Y-J, Mao Y-P, Ye R-X, Wang Q-Z, et al. Epidemiology, causes, clinical manifestation and diagnosis, prevention and control of coronavirus disease (COVID-19) during the early outbreak period: a scoping review. Infectious Diseases of Poverty. 2020;9(1):29.

14. Mandal S, Bhatnagar T, Arinaminpathy N, Agarwal A, Chowdhury A, Murhekar $M$, et al. Prudent public health intervention strategies to control the coronavirus disease 2019 transmission in India: A mathematical model-based approach. The Indian journal of medical research. 2020;151(2 and 3):190-9. 
15. Qian Y, Zeng T, Wang H, Xu M, Chen J, Hu N, et al. Safety management of nasopharyngeal specimen collection from suspected cases of coronavirus disease 2019. International journal of nursing sciences. 2020;7(2):153-6.

16. Wang J, Zhou M, Liu F. Reasons for healthcare workers becoming infected with novel coronavirus disease 2019 (COVID-19) in China. The Journal of hospital infection. 2020;105(1):100-1.

17. Sapkota D, Thapa SB, Hasseus B, Jensen JL. Saliva testing for COVID-19? British dental journal. 2020;228(9):658-9.

18. Xie X, Li Y, Sun H, Liu L. Exhaled droplets due to talking and coughing. Journal of the Royal Society, Interface. 2009;6 Suppl 6(Suppl 6):S70314.

19. Li Y, Ren B, Peng X, Hu T, Li J, Gong T, et al. Saliva is a non-negligible factor in the spread of COVID-19. Molecular oral microbiology. 2020.

20. Carpenter GH. The secretion, components, and properties of saliva. Annual review of food science and technology. 2013;4:267-76.

21. Yoshizawa JM, Schafer CA, Schafer JJ, Farrell JJ, Paster BJ, Wong DTW. Salivary Biomarkers: Toward Future Clinical and Diagnostic Utilities. Clinical Microbiology Reviews. 2013;26(4):781-91.

22. Zalewska A, Waszkiewicz N, López-Pintor RM. The Use of Saliva in the Diagnosis of Oral and Systemic Diseases. Disease Markers. 2019;2019:9149503.

23. Burki TK. Testing for COVID-19. The Lancet Respiratory Medicine.

24. Braz-Silva PH, Schussel JL, López Ortega K, Gallottini M. Oral lesions as an important marker for HIV progression. Dermatology online journal. 2017;23(9)

25. Henrique Braz-Silva P, Pallos D. SARS-CoV-2: What can saliva tell us? 2020.

26. Sabino-Silva R, Jardim ACG, Siqueira WL. Coronavirus COVID-19 impacts to dentistry and potential salivary diagnosis. Clinical oral investigations. 2020;24(4):1619-21.

27. Azzi L, Carcano G, Gianfagna F, Grossi P, Gasperina DD, Genoni A, et al. Saliva is a reliable tool to detect SARS-CoV-2. The Journal of infection. 2020.

28. Liu L, Wei Q, Alvarez X, Wang H, Du Y, Zhu H, et al. Epithelial cells lining salivary gland ducts are early target cells of severe acute respiratory syndrome coronavirus infection in the upper respiratory tracts of rhesus macaques. Journal of virology. 2011;85(8):4025-30.

29. Zhong F, Liang Y-j, Xu J-b, Chu M, Tang G-f, Hu F-y, et al. Continuously High Detection Sensitivity of Saliva, Viral Shedding in Salivary Glands and High Viral Load in Patients with COVID-19 (4/9/2020). Available at SSRN: https://ssrn.com/abstract=3576869 or http://dx.doi. org/10.2139/ssrn.3576869.

30. Xu H, Zhong L, Deng J, Peng J, Dan H, Zeng $X$, et al. High expression of ACE2 receptor of 2019-nCoV on the epithelial cells of oral mucosa. International Journal of Oral Science. 2020;12(1):8.
31. Williams E, Bond K, Zhang B, Putland M, Williamson DA. Saliva as a non-invasive specimen for detection of SARS-CoV-2. Journal of clinical microbiology. 2020:JCM.00776-20.

32. Wyllie AL, Fournier J, Casanovas-Massana A, Campbell M, Tokuyama M, Vijayakumar $P$, et al. Saliva is more sensitive for SARS-CoV-2 detection in COVID-19 patients than nasopharyngeal swabs. medRxiv. 2020:2020.04.16.20067835.

33. Kojima N, Turner F, Slepnev V, Bacelar A, Deming L, Kodeboyina S, et al. Self-Collected Oral Fluid and Nasal Swabs Demonstrate Comparable Sensitivity to Clinician Collected Nasopharyngeal Swabs for Covid-19 Detection. medRxiv. 2020:2020.04.11.20062372.

34. To KK, Tsang OT, Chik-Yan Yip C, Chan KH, Wu TC, Chan JMC, et al. 2020. Consistent detection of 2019 novel coronavirus in saliva. Clin Infect Dis doi:10.1093/cid/ciaa149.

35. Pasomsub E, Watcharananan SP, Boonyawat K, Janchompoo $P$ Wongtabtim G, Suksuwan W, et al. Saliva Sample as a Non-Invasive Specimen for the Diagnosis of Coronavirus Disease-2019 (COVID-19): a Cross-Sectional Study. medRxiv. 2020:2020.04.17.20070045.

36. To KK, Tsang OT, Leung WS, Tam AR, Wu TC, Lung DC, et al. 2020. Temporal profiles of viral load in posterior oropharyngeal saliva samples and serum antibody responses during infection by SARSCoV-2: an observational cohort study. Lancet Infect Dis doi:10.1016/ s1473-3099(20)30196-1.

37. Han MS, Seong MW, Kim N, Shin S, Cho SI, Park H, et al. Viral RNA Load in Mildly Symptomatic and Asymptomatic Children with COVID-19, Seoul. Emerging infectious diseases. 2020;26(10).

38. Becker D, Sandoval E, Amin A, De Hoff P, Diets A, Leonetti N, et al. Saliva is less sensitive than nasopharyngeal swabs for COVID-19 detection in the community setting. medRxiv. 2020:2020.05.11.20092338.

39. Du Z, Zhu F, Guo F, Yang B, Wang T. Detection of antibodies against SARS-CoV-2 in patients with COVID-19. Journal of Medical Virology.n/ $a(n / a)$.

40. Long Q-X, Liu B-Z, Deng H-J, Wu G-C, Deng K, Chen Y-K, et al. Antibody responses to SARS-CoV-2 in patients with COVID-19. Nature Medicine. 2020;26(6):845-8.

41. Parry JV, Perry KR, Mortimer PP. Sensitive assays for viral antibodies in saliva: an alternative to tests on serum. Lancet (London, England). $1987 ; 2(8550): 72-5$

42. McKie A, Vyse A, Maple C. Novel methods for the detection of microbial antibodies in oral fluid. The Lancet Infectious Diseases. 2002;2(1):18-24.

43. Lu B, Huang $Y$, Huang L, Li B, Zheng $Z$, Chen $Z$, et al. Effect of mucosal and systemic immunization with virus-like particles of severe acute respiratory syndrome coronavirus in mice. Immunology. 2010;130(2):254-61 